\title{
Electrostatic Assembly with Poly(ferrocenylsilanes)
}

\author{
Yujie Ma, ${ }^{1}$ Mark A. Hempenius, ${ }^{1}$ and G. Julius Vancso ${ }^{1,2}$
}

Submitted: September 26, 2006; Accepted: November 2, 2006

New frontiers in polymer science involve the incorporation of functional species into material systems. The electrostatic layer-by-layer (LBL) self-assembly technique constitutes a versatile tool for nano- and microscale fabrication of devices and novel material structures. Although a rapidly growing attention has been paid to this area, most of the studies conducted were based on organic polymeric electrolytes. Due to synthetic developments, new polymeric structures with inorganic elements and transition metals incorporated in the main chain have become accessible. With the development of new synthesis routes, organometallic poly(ferrocenylsilane) polycations and polyanions emerged. Their charged nature and water-solubility made them excellent candidates for the extension of electrostatic multilayer assembly to organometallic polymeric materials. The present review gives a concise summary on the LBL fabrication of organometallic thin films and microcapsules based on water-soluble poly(ferrocenylsilane) polyions. The unique functions of these structures come from the molecular structure of poly(ferrocenylsilanes), in which silicon atoms and redoxactive ferrocene units are present. In this context, the diverse application potentials of these organometallic multilayer structures are also discussed.

KEY WORDS: Poly(ferrocenylsilanes); layer-by-layer self-assembly; responsive polymers; redox; multilayer microcapsules; water-soluble; selective deposition

\section{INTRODUCTION}

The development and multidisciplinary broadening of materials science necessitates the design and synthesis of new functional polymeric materials. Macromolecules containing inorganic elements or organometallic units have attracted growing attention since these materials present very interesting properties, as they may combine novel optical, electrical, magnetic and chemical characteristics with the processability of polymers $[1,2]$.

Poly(ferrocenylsilanes) (PFS), composed of alternating ferrocene and silane units in the polymer

This article is dedicated to Professor Ian Manners in honor of his great scientific accomplishments, with friendship and sincere respect.

${ }^{1}$ Department of Materials Science and Technology of Polymers, $\mathrm{MESA}^{+}$Institute for Nanotechnology, University of Twente, $\mathrm{P}$. O. Box 217, 7500 AE, Enschede, The Netherlands

${ }^{2}$ To whom correspondence should be addressed.

E-mail: g.j.vancso@tnw.utwente.nl main chain, belong to this class of materials. Although oligomers with degrees of polymerization up to 10 were first obtained by Rosenberg in a condensation polymerization [3], the real breakthrough has been realized by the group of Manners. Fast and impressive progress in the chemistry of these polymers followed after the discovery of a thermal ring-opening polymerization (ROP) route of siliconbridged ferrocenophanes in the early 1990s [4]. Later on, living anionic and transition metal-catalyzed polymerization methodologies were also established, giving access to well-defined, monodisperse poly(ferrocenylsilane) homo- and block copolymers $[5,6]$.

The distinctive structural features of poly(ferrocenylsilanes) come from the silicon and iron atoms in the main chain, which make them valuable in the development of surface nano- and microstructuring strategies [7]. PFS were found to be effective resists in reactive ion etching processes due to the formation of an etch resistant iron/silicon oxide layer [8]. This resulted in the surface patterning applications of PFS 
using soft lithographic techniques as well as block copolymer lithography $[9,10]$. Phase separated PFS block copolymer thin films were also reported to be catalytically active for the synthesis of carbon nanotubes [11]. One particularly important property of PFS is their unique redox-activity. Oxidation and reduction of PFS can be performed by chemical reactions, where the extent and reversibility of oxidation were only reported recently [12]. Alternatively, the oxidation and reduction process of PFS is more precisely controlled using electrochemistry [13]. Oxidation of iron centres in PFS changes its electrical, optical and physical properties. Previous studies in our group on selfassembled end-functionalized PFS monolayers on gold revealed electrochemically induced morphology and volume/thickness changes [14]. Atomic force microscopy (AFM) based single molecule force microscopy (SMFS) measurements on poly(ferrocenylsilane) single chains showed significantly increased Kuhn length and segment elasticity after oxidation, demonstrating redox-induced changes of the torsional potential energy landscape [15].

With their significant industrial and commercial value in bio-related and medical applications, watersoluble polymers are becoming increasingly important in recent years. Although water-soluble organic macromolecules have been widely studied, their inorganic and organometallic counterparts are largely unexplored [2]. The macromolecular properties of poly(ferrocenylsilane) depend, to a large extent, on the substituents on silicon. Along with other characteristics, such as the crystallinity [13a, 16] and glass transition temperature [6], the solubility of PFS [17-22] can be tuned by varying the size and type of the substituents. Modification of the polymer side groups has been shown to give access to watersoluble PFS [18-22]. Homopolymers of water-soluble PFS have potential uses as electrode modifiers and redox-active polymeric electrolytes for which the ionic conductivity might be tuned by oxidation of the iron centres. These materials may also be useful in redox-controlled drug delivery applications since various water-soluble ferrocenium salts have been shown to display anti-cancer activity [23]. Watersoluble block copolymers with a poly(ferrocenylsilane) polyelectrolyte block, on the other hand, can self-assemble in aqueous media and the resulting micellar and vesicular aggregates may demonstrate redox-tunable encapsulation properties and emulsifying abilities for heterogeneous catalysis [24].

The most interesting aspect of the processabilities of PFS polyelectrolytes is the use of ionic interactions to deposit these polymers onto substrates. The so-called electrostatic layer-by-layer (LBL) technique is based on sequential adsorption of charged polyelectrolyte species to build up multilayered polymeric thin films with controlled thickness and composition [25]. One of the attractive advantages of this methodology is that thin films can be tailor-made to display desired chemical and physical properties by the choice of specific polyelectrolyte material [26]. Aqueous processing enables synthetic as well as natural polyelectrolytes to be assembled to thin films for a variety of applications, ranging from electroluminescent devices to biosensor arrays [27]. However, in its 15 years of development, the vast majority of polyelectrolyte species studied are organic materials. The accessibility of water-soluble PFS polycations and polyanions enabled the fabrication of organic-organometallic as well as all-organometallic multilayers. A major extension of the LBL method onto curved surfaces resulted in multilayercoated colloids and eventually, polyelectrolyte hollow capsules [28]. These micro- and nanocapsule systems offer plenty of promising applications in different areas such as biotechnology, medicine, catalysis, optics as well as electronics [26]. In this review, the discussion is focused on organometallic multilayers and microcapsules based on electrostatic self-assembly of water-soluble poly(ferrocenylsilane) polyelectrolytes. First the synthesis and properties of PFS polyelectrolytes as well as their defined self-assembly process are addressed; then the various potential application of these novel materials are summarized, with special emphasis on aspects related to the redoxresponsive properties of PFS.

\section{WATER-SOLUBLE POLY(FERROCENYL- SILANE) POLYELECTROLYTES}

\subsection{Synthesis}

The synthesis of water soluble poly(ferrocenylsilane) polyelectrolytes involves the ring-opening polymerization (ROP) of a silicon-bridged ferrocenophane followed by side-group modifications [18-22]. The starting silaferrocenophane monomers (Scheme 1) [18] are obtained from the reaction of $1,1^{\prime}$-dilithioferrocene with a dichloroorganosilane $\left(\mathrm{RR}^{\prime} \mathrm{SiCl}_{2}\right)$, in the presence of a complexing agent (tetramethylethylenediamine, TMEDA) [2]. The corresponding high molar mass polymers are readily accessible by thermal [4] and transition metal catalyzed 


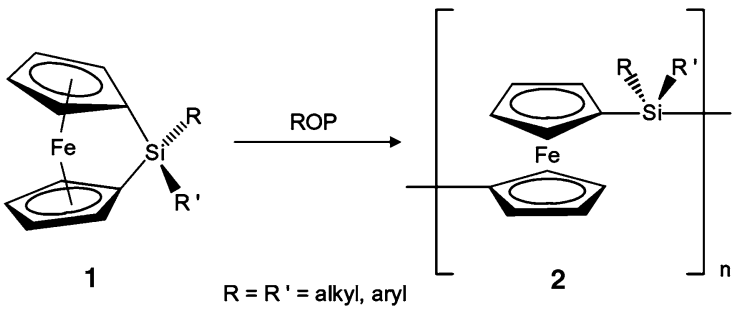

Scheme 1. Ring-opening polymerization (ROP) of silicon-bridged ferrocenophanes $\mathbf{1}$ leads to poly(ferrocenylsilanes) $\mathbf{2}$.

ROP [5, 29]. Transition metal catalyzed ROP is a relatively mild method since it occurs in solution and at ambient temperature. With the use of a silane (such as $\mathrm{Et}_{3} \mathrm{SiH}$ ), it also provides the advantage of controllable molar mass and architectures [30].

Many functionalities (such as polar or ionic moieties) do not tolerate the highly basic dilithioferrocene or the reactive chlorosilanes, are incompatible with the reactive strained monomer itself, or hinder monomer purification. Thus, the synthetic route leading to poly(ferrocenylsilane) polyelectrolytes often necessitates a side-group modification step after polymerization [21]. Figure 1 displays the water soluble poly(ferrocenylsilane) polyelectrolytes that have been studied in the electrostatic LBL selfassembly. Starting from poly(ferrocenyl(3-chloropropyl)methylsilane), nucleophilic substitution reactions give rise to a series of highly water-soluble PFS polyelectrolytes, both cationic $(\mathbf{3}, \mathbf{4}, \mathbf{6})$ and anionic $(\mathbf{7}, \mathbf{8})$. PFS with cyclic disilyl moiety protected aminoalkynyl nucleophiles provided anionic polyelectrolytes $\mathbf{9}$ and 10 [18]. However, an alternative approach involving the functionalization of the monomer and subsequent polymerization has also been shown to produce cationic water-soluble PFS. Monomers containing 5-coordinate silicon is first synthesized through the treatment of $\mathbf{1}\left(\mathrm{R}=\mathrm{Me}, \mathrm{R}^{\prime}=\mathrm{Cl}\right)$ with an aryl lithium reagent in THF. Polyelectrolyte $\mathbf{5}$ is obtained by polymerization of this monomer and subsequent quaternization of the amine [31].

Both cationic $(\mathbf{3}, \mathbf{4})$ and anionic $(\mathbf{8})$ water-soluble PFS polyelectrolytes have been studied by viscometry measurements in water, with minimal salt concentrations. The results exhibit typical behaviour of polyelectrolyte solutions, i.e. a strong increase of reduced viscosity $\left(\eta_{\mathrm{sp}} / C, \eta_{\mathrm{sp}}\right.$ is the specific viscosity) with decreasing polymer concentrations $[12,20]$. Cationic species 6 has been shown to form aggregates in water and display lower critical solution temperature

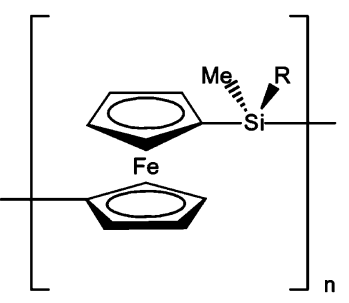

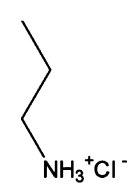

$\mathbf{R}=$
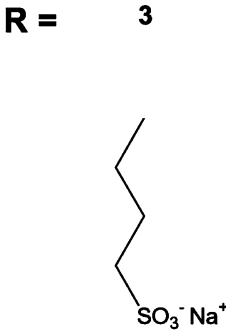

7

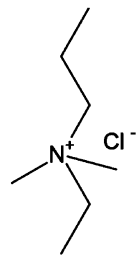

4

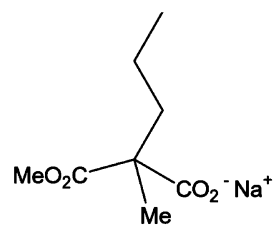

8

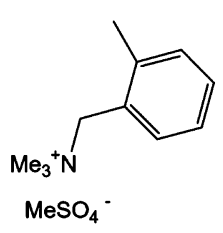

5

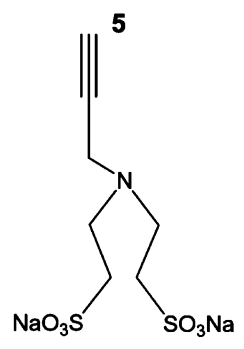

9

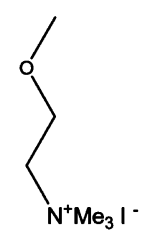

6

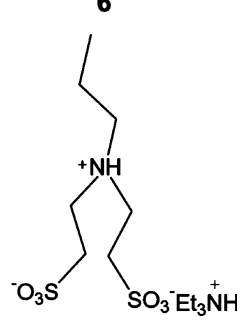

10

Fig. 1. Water soluble poly(ferrocenylsilane) polyelectrolytes that have been studied in the electrostatic LBL self-assembly. 
(LCST) near $40^{\circ} \mathrm{C}$, due to the presence of the oligo(ethylene glycol) side chains.

\subsection{Redox Chemistry}

Ferrocene $(\mathrm{Fc})$ groups are redox-active. Due to the ferrocene containing backbone, PFS belongs to the class of stimuli-responsive polymers [32]. Many attempts to reversibly oxidize and reduce PFS by chemical [17, 33] as well as electrochemical [13] methods have already been reported. PFS polyelectrolytes have potential applications as electrode materials and redox-active polymeric electrolytes for which the ionic conductivity could be tuned by oxidation and reduction of the ferrocene units [23]. Although effective chemical oxidation and reducing agents for PFS in organic solvents (such as dichloromethane, THF, and toluene) have been relatively well-developed, identification of good water-soluble oxidizing and reducing agents is not so straightforward.

Despite the hydrolysis of ferric chloride $\left(\mathrm{FeCl}_{3}\right)$ in neutral to alkali solutions, we found that slightly acidic ( $\mathrm{pH}$ 4-5) aqueous solutions of $\mathrm{FeCl}_{3}$ can effectively oxidize PFS polyelectrolytes in water. Corresponding UV/Vis spectra are shown in Fig. 2a. Accompanied by an almost instantaneous solution colour change from yellow-orange to green-blue, UV/ Vis spectroscopy confirmed the appearance of a new peak at $\lambda=637 \mathrm{~nm}$ which is characteristic of ferrocenium [12].

Water-soluble PFS reducing agents were also reported recently, namely ascorbic acid (vitamin C) and dithiothreitol (DTT) [12]. PFS polycation 4 was used as the test polyelectrolyte species. $\mathrm{A} \mathrm{FeCl}_{3^{-}}$ oxidized polycation was reduced satisfactorily using ascorbic acid, with an immediate solution colour change back to its original yellow-orange colour. In
Fig. 2b, the redox-reversibility was shown as the reappearance of the ferrocene absorbance at $\lambda=447 \mathrm{~nm}$. By carefully tuning the $\mathrm{pH}$ value of the applied aqueous ascorbic acid solutions, the reduced PFS polyelectrolytes are stable under storage in water and ambient conditions for at least 1 month (Y. Ma, unpublished results).

However, organic solvents based oxidants and reducing agents have also been reported to be able to reversibly change the redox states of water-soluble PFS polyelectrolytes. In the work from the group of Manners [34], hexane solutions of iodine (as oxidant) and THF solutions of decamethylferrocene (as reducing agent) were used to accomplish multiple redox cycles of the ferrocene units in LBL fabricated PFSdefect colloidal photonic crystals (CPCs) [35].

\section{LBL ELECTROSTATIC ASSEMBLY OF POLY(FERROCENYLSILANES)}

Poly(ferrocenylsilane) polyelectrolytes have been applied in the electrostatic LBL self-assembly process to fabricate ultrathin films, both on planar substrates and on colloidal particles. Supported multilayer thin films and free-standing microcapsules, composed of full organometallic as well as organometallic-organic hybrid materials were obtained. The fabrication and properties of these self-assembled superlattice structures are discussed below.

\subsection{Substrate-Supported Multilayer Thin Films}

\subsubsection{Multilayer Formation and Characterization}

Before the development of fully organometallic multilayers, examples based on organic polymers and
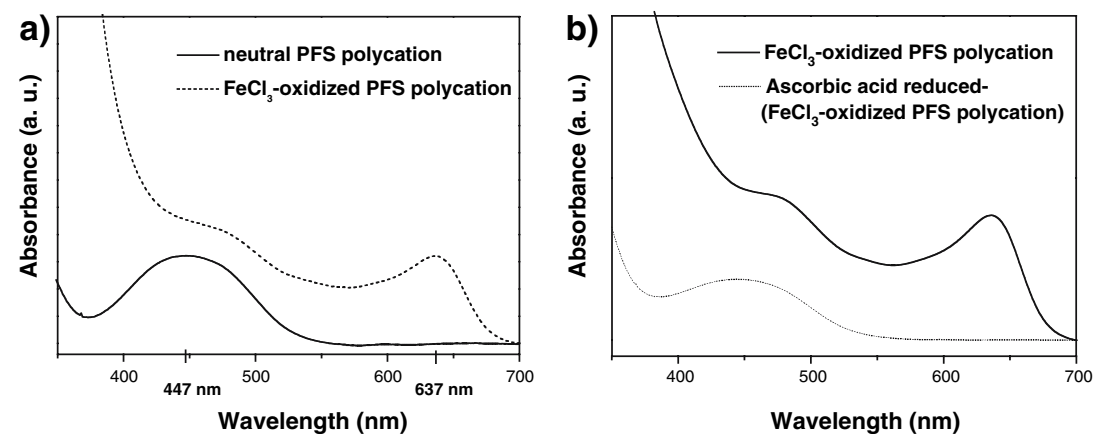

Fig. 2. UV-visible spectra of PFS polycation 4 (aqueous solutions): (a) after oxidation with $\mathrm{FeCl}_{3}$ (at pH 4-5) (spectrum of PFS polycation is also shown); (b) after reducing back with ascorbic acid (spectrum of oxidized PFS polycations is also shown). Reproduced with permission from [12]. Copyright 2006 Springer Science + Business Media, Inc. 
organometallic PFS were first shown around the year 2000 [19, 36]. In these examples, cationic PFS polyelectrolytes $(\mathbf{3}, \mathbf{5}, \mathbf{6})$ were used, while for the anionic polyelectrolyte species poly(styrene sulfonate) (PSS) or poly(sodium vinylsulfonate) were chosen. The successful exploration of these hybrid multilayer thin films was soon extended to the fabrication of fully organometallic superlattices solely composed of PFS polyelectrolytes. Multilayers were deposited on (but are not restricted to) quartz slides, silicon wafers, gold substrates, and quartz crystal microbalance substrates [36-38]. For gold substrates, normally a predeposited thiol monolayer (such as sodium 3mercapto-1-propanesulfonate, 11-mercaptoundecanoic acid, or 2-aminoethanethiol hydrochloride) was applied to impart negative or positive charges to the surfaces. Polyelectrolytes were subsequently deposited in an alternative fashion onto the charged substrates from aqueous solutions $(2-10 \mathrm{mM}$, based on the molar mass of the repeating unit) with low to medium ionic strength $(0-0.5 \mathrm{M} \mathrm{NaCl})$. The procedure can be continued until a desired number of bilayers is achieved, which can range from a few to hundreds. Until now, for all the planar supported organic-organometallic and fully organometallic multilayer systems studied, linear growth profiles were observed. This suggests the formation of welldefined multilayers [39]. Depending on the type of substrates used, different characterization methods were applied to follow the multilayer formation process.

The simplest way to monitor the growth profile of LBL deposited PFS multilayers is by $\mathrm{UV} / \mathrm{Vis}$ spectroscopy. In the reduced state, PFS has two characteristic absorbance bands: an intense ligand-tometal charge transfer transition (LMCT) at $220 \mathrm{~nm}$ and a weaker visible $d-d$ band centered at $450 \mathrm{~nm}$ [40]. When multilayers made from polyions 5 and 9 were prepared on quartz substrates, a linear increase of absorbance at both bands was observed (Fig. 3). From the figure it is easy to see that the strong absorbance at $220 \mathrm{~nm}$ is more reliable since the weak and broad $d-d$ absorption tends to result in larger errors associated with resolving the peak maximum.

Information on film thickness increase with increased numbers of bilayers was normally obtained from ellipsometry measurements of multilayers prepared on silicon wafers. Unlike UV/Vis spectroscopy that relies on the molar extinction coefficient of deposited absorbing materials, ellipsometry is a more universal physical method in determining thin film thickness of any material based on refractive index
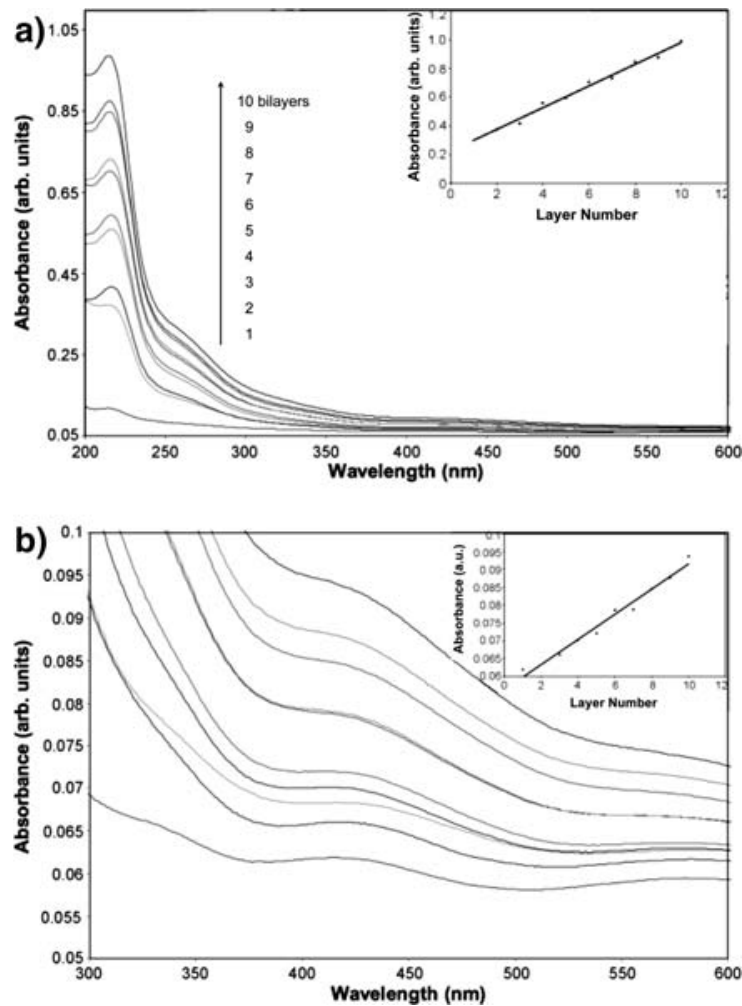

Fig. 3. UV-Vis spectra for PFS multilayers made from polycation 5 and polyanion 9 corresponding to layers 1-10. (a) Region of the $\mathrm{UV} /$ Vis spectra showing the PFS LMCT at $\sim 220 \mathrm{~nm}$. (b) Scale expanded spectra showing the PFS $d-d$ transition at $\sim 420 \mathrm{~nm}$. Insets show the linear increase in absorbance with the layer numbers [38]. Reproduced by permission of The Royal Society of Chemistry.

contrast. Moreover, ellipsometry measures the change in polarization of light upon reflection, while $\mathrm{UV} / \mathrm{Vis}$ spectroscopy studies the light absorbance. Thus PFS multilayers deposited on optically nontransparent substrates can be characterized by ellipsometry but not by transmission UV/Vis spectroscopy. Ellipsometry spectra were taken after each deposited bilayer. In Fig. 4, ellipsometric spectra are shown for a bare substrate and after deposition of three, six and nine bilayers of PFS polyion pair $\mathbf{3} / \mathbf{8}$. The variation in $\tan \Psi$ and $\cos \Delta$ is approximately uniform over the entire wavelength range, indicating a wavelengthindependent refractive index [37]. Assuming a refractive index of $n=1.687$ derived from independent measurements, the spectra can be fitted to interpret the thickness of the multilayers. In the example given in Fig. 4, a linear increase of multilayer thickness as a function of the number of deposited polyelectrolyte bilayers was observed. This is a confirmation of the formation of well-defined multilayers that was indicated from the above $\mathrm{UV} / \mathrm{Vis}$ absorbance 

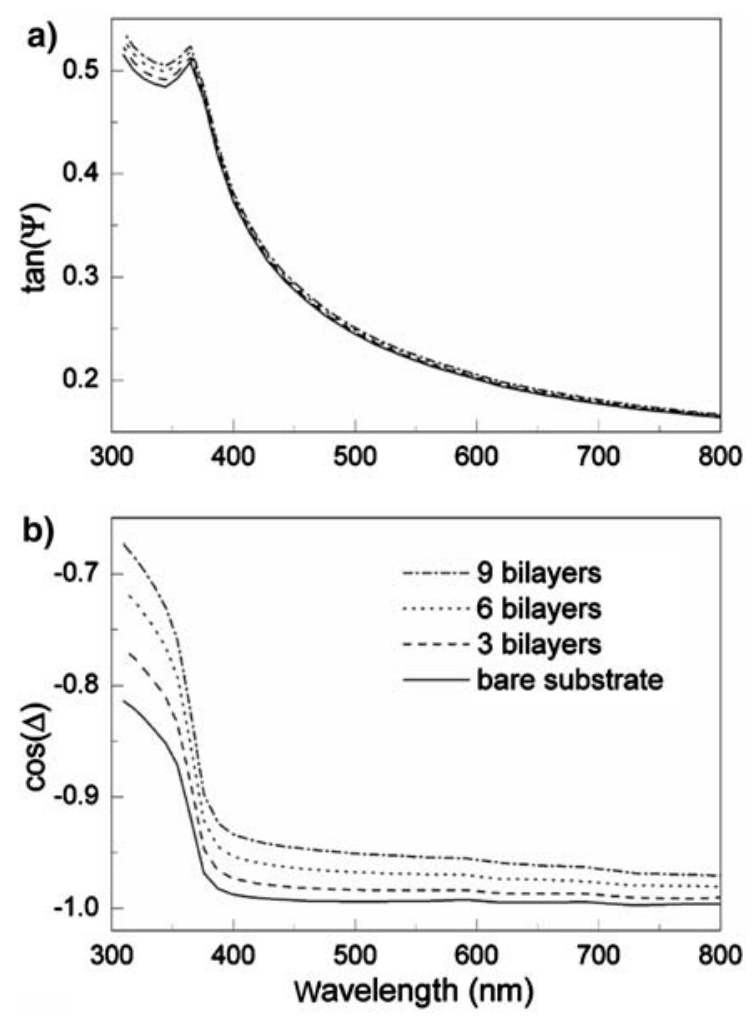

Fig. 4. Ellipsometric spectra of three, six and nine PFS bilayers made from polycation $\mathbf{3}$ and polyanion $\mathbf{8}$ on silicon. Reprinted with permission from [37]. Copyright 2002 American Chemical Society.

spectroscopy results. The fitting gave a thickness value of $0.4 \mathrm{~nm}$ for the contribution of a single bilayer. Thicker films (with bilayer thicknesses up to $\sim 5 \mathrm{~nm}$ ) were also prepared by varying the ionic strength of the polyelectrolyte solutions from which the layers were deposited [34, 36, 41-43]. Very recently, we carried out a systematic study on PFS multilayer deposition from aqueous solutions with varying ionic strength and polymer concentrations. The film thicknesses showed a square root dependence on solution salt concentration [43], which had been observed before for other polyelectrolyte multilayer systems [44].

For complementary purposes, X-ray photoelectron spectroscopy (XPS) served as a very useful tool to measure the surface composition of these organometallic thin films. XPS measurements have been performed on multilayer thin films on quartz substrates as well as on gold substrates. Figure 5 shows a survey scan of a multilayer film composed of 20 bilayers of PFS polyions $\mathbf{3}$ and $\mathbf{8}$. All the expected elements can be found in the spectrum. From further

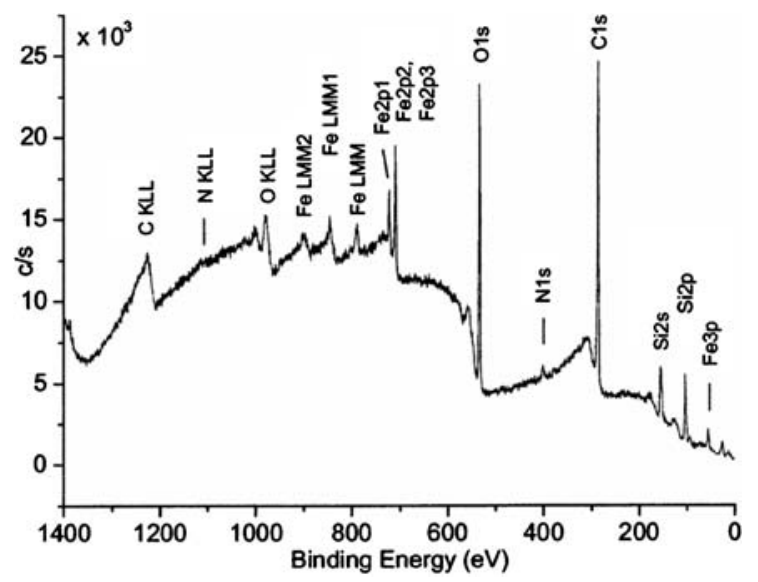

Fig. 5. XPS survey spectrum of a multilayer thin film (20 bilayers on quartz) composed of PFS polyelectrolyte pair 3 and $\mathbf{8}$. Reprinted with permission from [37]. Copyright 2002 American Chemical Society.

atomic concentration analysis, the experimental composition of a bilayer unit was found to be in agreement with the expected one [37]. The group of Manners compared the XPS spectra of LBL superlattices made of different bilayer numbers [36]. The results illustrated that the region for $\mathrm{Fe}(2 \mathrm{p})$ increased in relative intensity with multilayer buildup, confirming the successful incorporation of PFS units into the thin film structure. Since their experiments were conducted on samples deposited on gold substrates, the greatly diminished Au peaks in comparison to the top trace was an indication of the complete surface coverage of the multilayers [45].

Another complementary method for monitoring multilayer buildup makes good use of the native redox-responsive nature of poly(ferrocenylsilanes). PFS can be reversibly oxidized and reduced electrochemically [13]. A typical voltammogram shows two oxidation waves, indicating intermetallic coupling between neighbouring iron centres in the polymer chain [13a]. The first oxidation wave has been attributed to oxidation of ferrocene centres having neutral neighbouring units. The remaining ferrocene units, predominantly those in positions next to the oxidized ones, will be oxidized in the second wave and at higher potentials. In order to study the electrochemical properties of multilayers composed of PFS polyions by cyclic voltammetry (CV), thin films were prepared on gold electrodes. Again for the polyion pair $\mathbf{3}$ and $\mathbf{8}$, cyclic voltammograms were recorded for samples having an increasing number of bilayers. From the integration of the area under the obtained voltammetric peaks, the charge involved in 
the redox processes $Q$ could be calculated and converted to the ferrocene surface coverage $\Gamma$, from the relation $\Gamma=Q / n F A$, where $n$ is the number of transferred electrons in the process (in this case $n=1), F$ is the Faraday constant $\left(96,485 \mathrm{C} \mathrm{mol}^{-1}\right)$, and $A$ is the geometric surface area of the gold electrode $\left(0.44 \mathrm{~cm}^{2}\right)$ [46]. Figure 6 shows the plot of the calculated $\Gamma$ as a function of the number of bilayers, demonstrating once again the linear increase of ferrocene surface coverage with an increasing number of bilayers [37].

An alternative way to obtain the PFS surface coverage, i.e. the adsorbed amount of material, is by quartz crystal microbalance (QCM) measurements. Multilayers were prepared on special electrodes (often gold or silver) and frequency changes were monitored for each deposited (bi)layer. The frequency decrease upon material absorption has a linear relationship with the adsorbed amount by the Sauerbrey equation $\Delta F=-1.832 \times 10^{8} \mathrm{M} / \mathrm{A}$, where $A$ is the surface area of the resonator [47]. In such

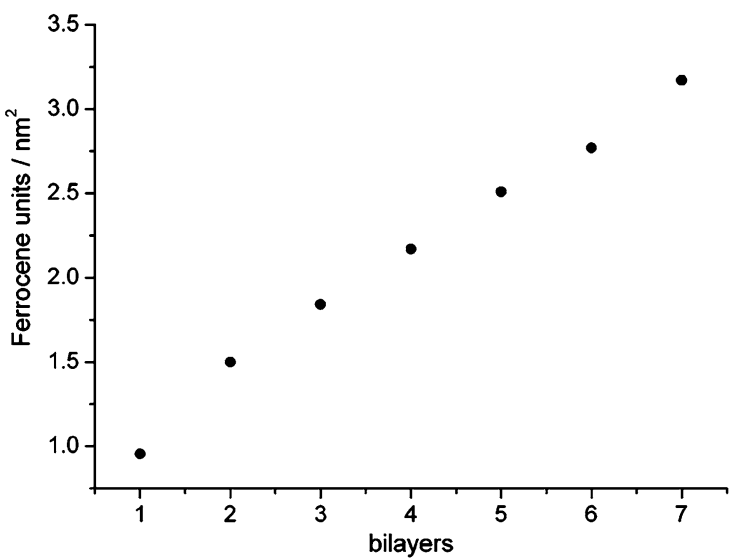

Fig. 6. Surface concentrations of ferrocene units as a function of the number of bilayers as determined by cyclic voltammetry for PFS polyion pair 3 and $\mathbf{8}$. Reprinted with permission from [37]. Copyright 2002 American Chemical Society. way, a linear frequency decrease implies a linear growth profile. However, slight non-linearity was often observed in the deposition of early layers of multilayer systems that had overall linear growth behaviour [36, 48].

Unlike the above-mentioned indirect characterization methods, a more direct route can be followed to visualize these multilayer thin films. By coating the top surface of the organometallic polymeric superlattices with a thin gold layer, their growth and architectures can actually be straightforwardly imaged by transmission electron microscopy (TEM). TEM imaging of multilayer structures was originally developed to locate interfaces between inorganic-organic hybrid multilayer blocks [49]. Characterization of PFS multilayers by TEM may allow the effect of polymer structure, composition and charge density on thin film thicknesses to be established. Figure 7 gives an example of TEM images for the cross-section of an organic-PFS hybrid multilayer (composed of PFS polycation 5 and PSS) and a full PFS multilayer (composed of PFS polycation 5 and polyanion 10) [38].

\subsubsection{Thin Film Properties}

One of the most attractive potentials of multilayer films composed of poly(ferrocenylsilane) polyelectrolytes obtained by electrostatic assembly is the application as ultrathin electroactive coatings. The LBL method itself also provides the additional advantage of an accurate control over the film thickness and redox surface concentration. In the previous section, cyclic voltammetry was used to address the amount of surface deposited ferrocene units. This is done by recording the redox properties of these films, as shown in the cyclic voltammograms. In Fig. 8, the CVs of thin films composed of polyion pair $\mathbf{3}$ and $\mathbf{8}$ show the two oxidation and reduction waves typical of poly(ferrocenylsilanes). Under the
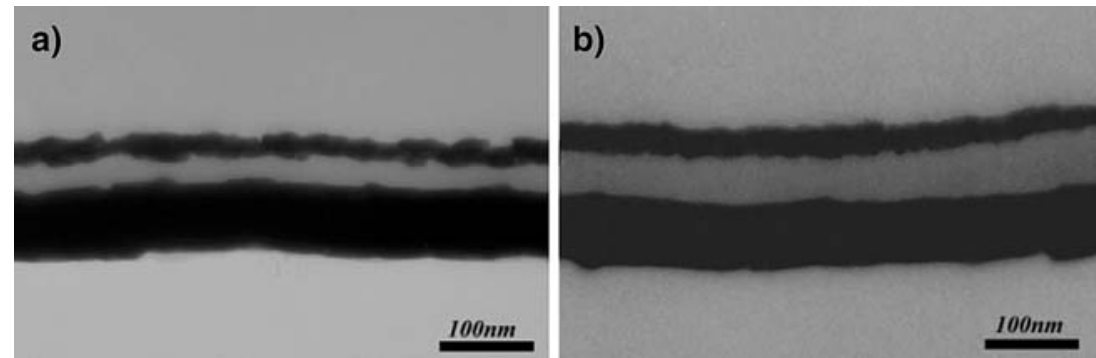

Fig. 7. TEM images for 20 bilayers of (a) PFS polycation 5/PSS and (b) PFS polycation $\mathbf{5} /$ PFS polyanion $\mathbf{1 0}$ [38]. Reproduced by permission of The Royal Society of Chemistry. 


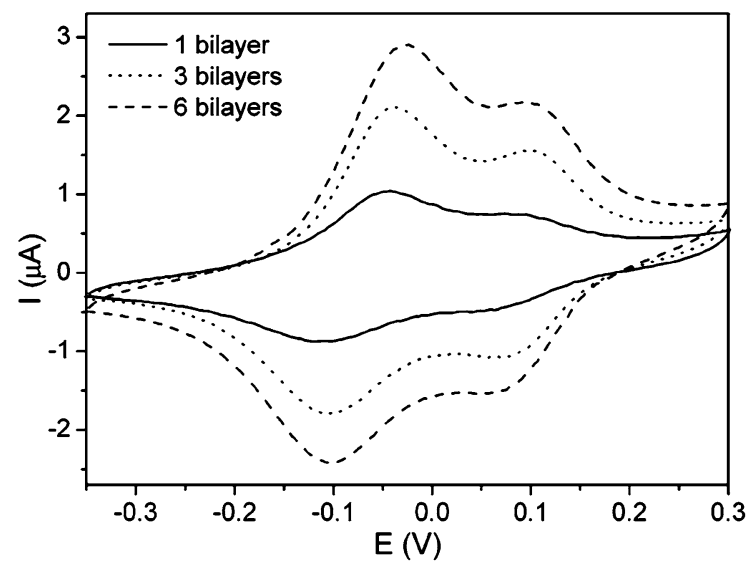

Fig. 8. Cyclic voltammogram of one, three and six PFS bilayers composed of polyions $\mathbf{3}$ and $\mathbf{8}$ on gold electrodes featuring a monolayer of sodium 3-mercapto-1-propanesulfonate. Scan rate was $30 \mathrm{mV} / \mathrm{s}$. The electrolyte was $0.1 \mathrm{M}$ aqueous $\mathrm{NaClO}_{4}$ solutions and the potential was referenced to an $\mathrm{Hg} / \mathrm{HgSO}_{4}$ reference electrode. Reprinted with permission from [37]. Copyright 2002 American Chemical Society.

same scanning rate $(30 \mathrm{mV} / \mathrm{s})$, the apparently increasing peak area is a clear indication of the increased amount of redox sites. The relative ratio between oxidation peak areas in the CVs is $2: 1$, implying a different charge transfer mechanism from what was obtained from the study of PFS monolayers on gold electrodes [13c]. In the first oxidation wave more than half of the redox sites are oxidized. This may be related to the water solubility of these polyelectrolytes, which was enhanced by the formed ferrocenium sites on the polymer main chain.

It has been reported that the surface wettability of sequentially adsorbed organic polyelectrolyte layers is controlled primarily by the outmost surface layer $[50,51]$. Thus, it is possible to create surfaces with molecularly tuneable wetting characteristics by simply changing the nature of the outmost adsorbed polyelectrolyte layer. This can be accomplished via the use of surface layers with different chemical structures or by controlling the surface composition of a single bilayer combination [50]. Moreover, contact angle (CA) measurements also serve as an important technique to gain information about the level of interlayer interpenetration present in sequentially adsorbed polyelectrolyte layers [51].

The wettability properties of hybrid polyelectrolyte multilayers composed of the organic polyanion PSS and organometallic PFS polycation 5 on gold substrates were examined using advancing water contact angle measurements. The results, as shown

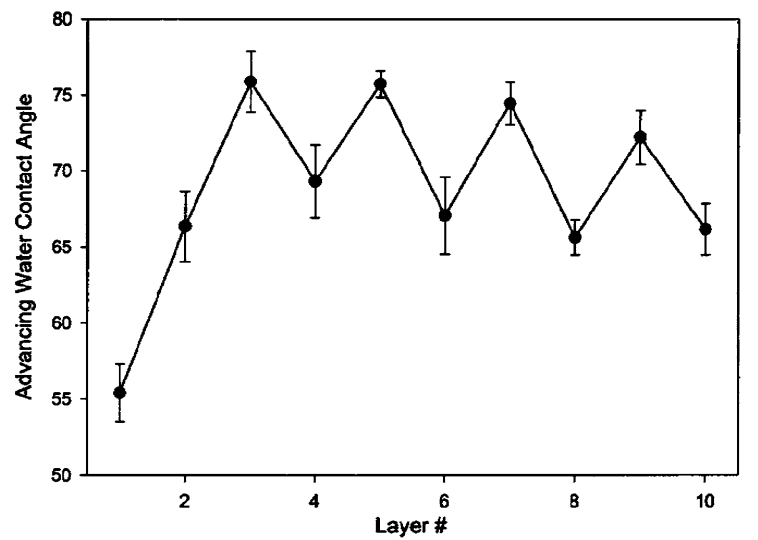

Fig. 9. Advancing water contact angles on PSS anion (odd numbered layers) and PFS polycation 5 (even numbered layers) terminated-multilayer films on gold substrates. Reprinted with permission from [36]. Copyright 2000 American Chemical Society.

in Fig. 9, demonstrate the systematic and consistent alternation of the advancing contact angle value between $75 \pm 2^{\circ}$ for PSS-terminated surfaces and $67 \pm 5^{\circ}$ for PFS terminated surfaces [36]. This gives the evidence that PFS-terminated surfaces are slightly more hydrophilic than PSS-terminated multilayer surfaces. In addition, the role that the outmost layer has on multilayer surface wettability properties is emphasized again.

Topographical properties of multilayer thin films could be examined by AFM measurements [52]. It has been reported that polyelectrolyte multilayer growth will smoothen the roughness of a substrate [53]. This phenomenon was partially explained by the notion that the deposition of a uniform thin film is expected to follow the substrate surface morphology [54]. Surface morphologies of gold or silicon supported PFS multilayers were also studied by AFM. Figure 10 shows tapping-mode AFM height images obtained from multilayers in the different stages of LBL assembly from PFS polyions 4 and 7 on silicon wafers. The films were deposited from polyelectrolyte solutions containing $0.5 \mathrm{M} \mathrm{NaCl}$. The root-meansquare (rms) roughness decreased from a value of 0.7 (with a predeposited PEI layer and one bilayer of PFS polyions) to 0.55 (after the deposition of 10 bilayers of PFS polyions), over a $2 \times 2 \mu \mathrm{m}^{2}$ scanned area. This result implied that the growth of the multilayers was uniform and followed the surface morphology of the substrate and confirmed the reported "smoothening" effect (Y. Ma, unpublished results). Similar results on organic-organometallic 

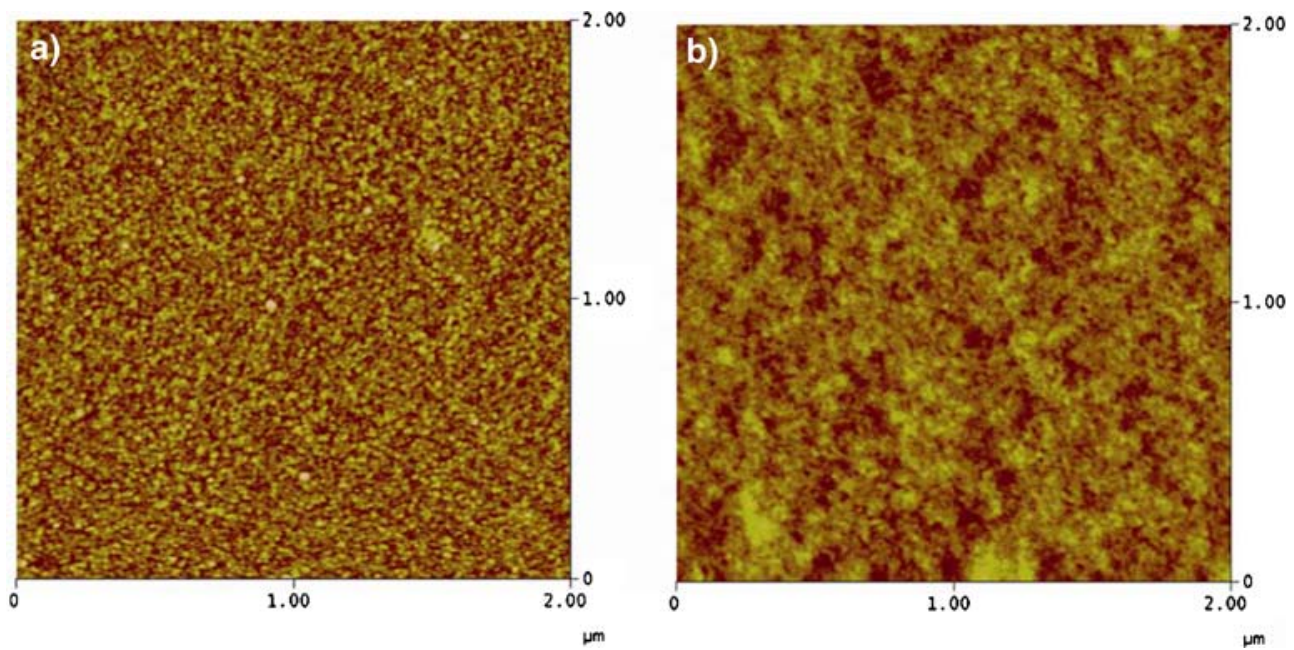

Fig. 10. Tapping mode AFM height images ( $z$ range is $10 \mathrm{~nm}$ for both images) of a silicon substrate with a predeposited PEI layer and only 1 bilayer of PFS polyions 4 and 7 (a) and additional 9 bilayers of the same polyelectrolytes (b).

hybrid multilayers deposited on gold substrates were reported as well [36].

It is worth mentioning that AFM can also serve as an alternative tool to estimate the thickness of multilayer films. This can be done by making a depression on the film surface using the AFM tip. The depth of the depression after it becomes constant is treated as the film thickness [54]. However, in many cases piled up material was observed along the edges of the depression, making the whole procedure difficult to control.

\subsection{Multilayer Capsules}

A further exploration of the electrostatic LBL technique was pioneered by the group of Möhwald in 1998, when fabrication, structure and properties of polyelectrolyte multilayer capsules were first reported [28]. The method involves colloidal-templated consecutive polyelectrolyte adsorption followed by decomposition of the templating core. The most fascinating aspect of these hollow capsule systems lies in the fact that due to the LBL preparation, the asmade stable microcapsules normally display permeability to small molecules but not to macromolecules [55]. The investigation of PFS polyelectrolyte multilayers on planar substrates provides the fundamental information to further fabricate and study microcapsules made of the same material. The responsive nature of PFS opens up new revenues to explore polyelectrolyte microcapsule systems that could specifically respond to redox-stimuli and correspondingly change their permeability to certain molecules.

Unlike traditional organic polyelectrolytes, PFS polyelectrolytes are relatively sensitive to solution $\mathrm{pH}$ changes. The stable $\mathrm{pH}$ range for PFS polyions is between 4 and 11 [22]. This brings complications in capsule fabrication, since the dissolution procedure for most of the well-established template materials (e.g. melamine formaldehyde, MF or silica particles) often involves strong acid or base treatments. Efforts have been made to prepare PFS capsules out of MF particles and silica particles [56], but it is difficult to guarantee the integrity of these capsules. Recently, systematically well-defined PFS capsule systems were established by the group of Vancso [42]. In a new context, PFS polyelectrolyte microcapsules were fabricated on metal carbonate $\left(\mathrm{MnCO}_{3}\right)$ microparticles. The mild dissolution conditions (EDTA, $\mathrm{pH}$ neutral) of these microparticles provided their essential suitability in the production of clean capsules with controllable integrity [57]. In Fig. 11, examples of PFS microcapsules containing six bilayers of polyion pair 4 and 7 are demonstrated. The confocal image recorded by using tetramethylrhodamine isothiocyanate (TRITC) labelled dextran $(4.4 \mathrm{kDa})$ as a fluorescence probe showed well-defined integrity of these capsules as well as their impermeability (over $90 \%$ ) to the probe molecules. Dried capsules were characterized by AFM. The obtained AFM height images could be used to further check capsule integrity and deduce capsule wall thickness [58]. 

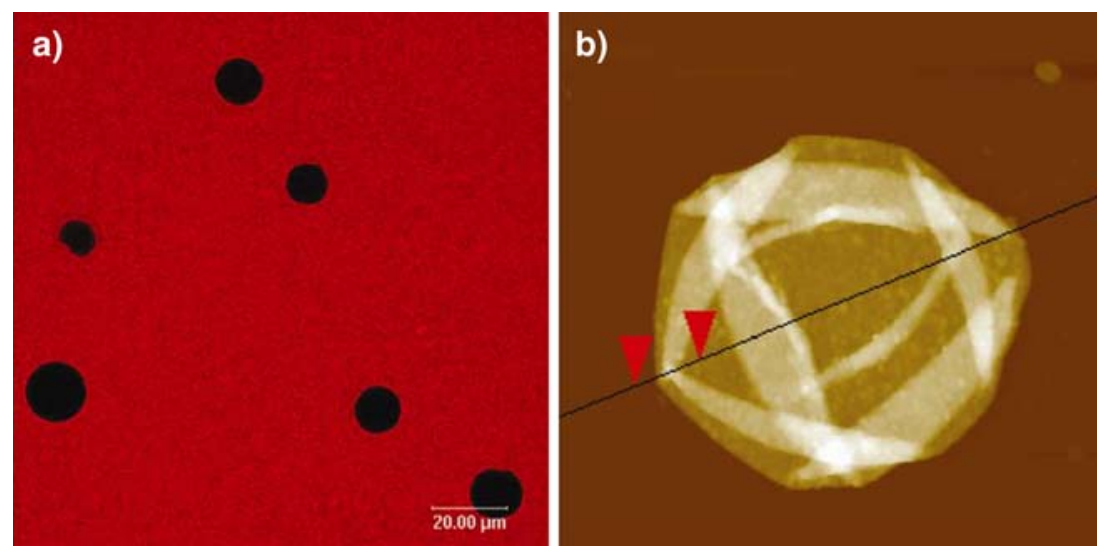

Fig. 11. (a) A confocal laser scanning micrograph (CLSM) showing the PFS microcapsules made from six bilayers of polyions $\mathbf{4}$ and $\mathbf{7}$ to be impermeable to tetramethylrhodamine isothiocyanate (TRITC) labelled dextran (4.4 kDa) molecules; (b) AFM height image of an air-dried capsule from the same sample as shown in the CLSM image, scan area: $15 \times 15 \mu \mathrm{m}^{2}$.

\section{APPLICATION POTENTIALS OF POLY(FERROCENYLSILANE) MULTILAYER ASSEMBLIES}

Since the LBL electrostatic self-assembly can be applied to construct and design complex polymeric architectures, numerous potential applications can be envisaged. Thin film applications range from coatings, compatibilization and surface protection [59], enzyme immobilization [60], biosensors [61], gas separation membranes [62], high charge density batteries [63], modified electrodes [64], etc. Polyelectrolyte multilayer microcapsules, on the other hand, may be used in areas such as medicine, delivery systems [65], catalysis, micro-containers and reactors [66]. The unique molecular structures of organometallic PFS polyelectrolytes also provide some special application potentials, which will be discussed in this section.

\subsection{Surface Patterning}

Patterned multilayers may have potential applications for producing complex optical or electrooptical devices, such as waveguides and display materials $[67,68]$. Early attempts for selective multilayer assembly on specific areas involve microcontact printing through the use of self-assembled monolayers (SAMs) as molecular templates [69, 70]. Later, non-lithographical means such as inkjet printing were introduced [71]. The development of new techniques, such as the "lift-off" approach [72], and the "polymer on polymer" stamping [73] were followed. Due to the co-existence of $\mathrm{Si}$ and $\mathrm{Fe}$ atoms in the main chain of poly(ferrocenylsilanes), PFS polymers are redox-active and resistant towards reactive ion etching $[8,74]$. Area-selective deposition of PFS polyelectrolytes can serve as an attractive method to obtain two-dimensionally patterned redox-active films, which have potential applications as electrochemically modulated diffraction gratings [75]. Moreover, patterned organometallic thin films may be also of interest as etch barriers in reactive ion etch processes. For this second purpose, it is essential to fabricate fully organometallic multilayers.

Our current approach to achieve patterned organometallic multilayer thin films is by the selective deposition of PFS polyelectrolytes on hydrophilic/ hydrophobically patterned substrates. Alternating acid $(\mathrm{COOH})$ and oligoethylene glycol (EG) functional surfaces are most commonly used as the template surfaces for the selective deposition of polyelectrolytes. Areas covered with oligomers of PEO were found to prevent adsorption of polyions due to enthalpic and entropic interfacial effects [68]. As a demonstration, we employed a patterned gold substrate with methyl-terminated alkanethiol (1-octadecanethiol) lines, separated by hydroxyl-terminated (11-mercapto-1-undecanol) SAMs. The resulting hydrophilic/hydrophobically patterned substrate proved to be very effective in PFS multilayer selective deposition. In Fig. 12, AFM height and friction force images of these patterned SAMs (top images) show minimal height contrast but a large contrast in friction force, with the hydroxyl-terminated lines corresponding to the high friction area. After the deposition of only one bilayer of PFS polyions 3 and $\mathbf{8}$ (Fig. 12 middle and bottom images), 

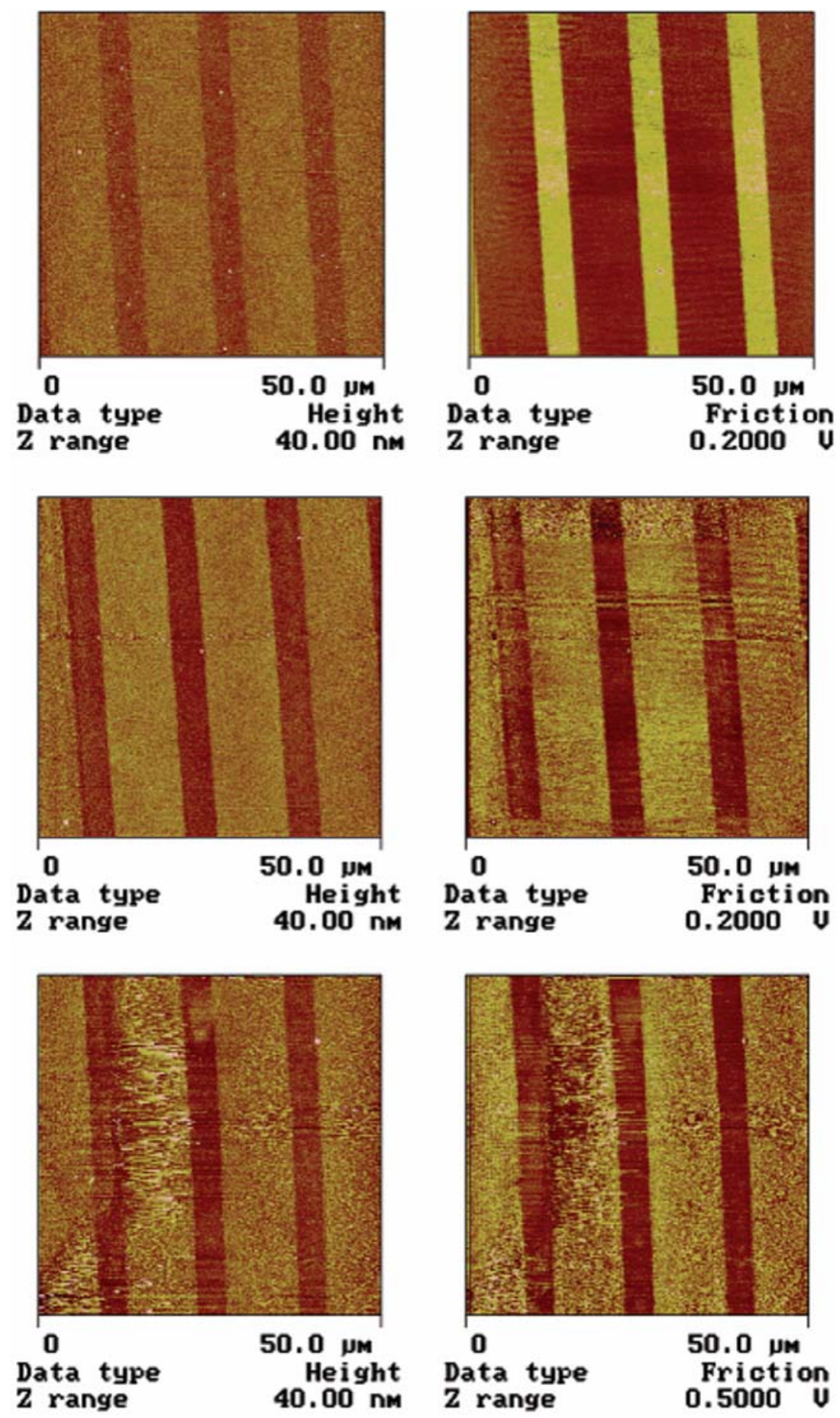

Fig. 12. AFM height (left) and friction force (right) images of patterned methyl- (broader lines) and hydroxyl- (thinner lines) alkanethiol selfassembled monolayers on gold (top) and of one poly(ferrocenylsilane) polycation $\mathbf{3}$ and polyanion $\mathbf{8}$ bilayer adsorbed on this prepatterned substrate. Adsorption sequence: cation-anion (middle), anion-cation (bottom). In both cases the bilayer is selectively adsorbed on the hydrophobic methyl-terminated areas. Reprinted with permission from [37]. Copyright 2002 American Chemical Society. 
height contrast increased and contrast in friction force was reversed. This is a clear indication that multilayers grow selectively on the methyl-terminated stripes. In addition, consistent selective deposition on the methyl-terminated area was observed also upon reversal of the deposition sequence. This strongly suggests that the selective deposition is most likely driven by favourable hydrophobic interactions between the methyl-terminated SAM and the hydrophobic poly(ferrocenylsilane) backbone. The hydroxyl-terminated regions prevent multilayer deposition, which probably is a result of hydrogen-bonding interactions with the solvent and interfacial energy minimization [37].

\subsection{Functional Microphotonic Devices}

Photonic crystals (PCs) are synthetic materials that have a spatially periodic dielectric constant modulation on the scale of the radiation wavelength [76]. They can suppress, slow or guide the flow of electromagnetic radiation in certain lattice directions so as to have promising application potentials for a variety of optoelectronic devices [77]. Analogous to the doping process of semiconductors, the functionality of PCs can be extended by the introduction of extrinsic defects, which will lead to optical defect states within the photonic band gaps or stop bands [78]. Recently, polyelectrolyte multilayers (PEMs) have been used to build planar defects into PCs, allowing for chemically active defects responsive to solvent vapour pressure, light, and thermal cycling $[35,79]$. To broaden potential applications in this direction, redox responsive poly(ferrocenylsilane) polyelectrolyte multilayers were also incorporated as planar defects in self-assembled CPCs [34]. The idea is to achieve precise and reversible tuning of the intergap transmitting state of the $\mathrm{CPC}$, by simple redox cycling.

As illustrated in Fig. 13a, the PFS planar defect was prepared by LBL growing a PFS multilayer from polyions 5 and 9 onto a flat polydimethylsiloxane (PDMS) sheet. Following the "polymer-transfer printing", the PFS multilayers were then transferprinted onto the surface of a planar CPC consisting of silica spheres. The desired heterostructure was completed by the growth of a second CPC on top of the defect and clearly visualized by SEM (Fig. 13b). Desired thickness was accomplished by either varying the number of bilayers grown onto the bottom CPC or by printing several multilayers in succession. The bilayer thickness was deduced as $4.8 \mathrm{~nm}$ as from ellipsometry measurements.

The defect wavelength was subsequently tuned by chemical oxidation and reduction cycles. A hexane solution of iodine and a THF solution of decamethylferrocene were used, respectively, as the oxidant and reducing agent. After the first conditioning cycle, an almost completely reversible and reproducible tuning of the defect states was achieved, as demonstrated in Fig. 14b. Complemented by ellipsometry experiments, oxidation of the PFS defect multilayer was reported to lead to a $4 \mathrm{~nm}$ red-shift of the defect position due to a $14 \%$ increase in thickness and a $6.5 \%$ increase of the refractive index of the PFS multilayers. Moreover, the defect wavelength can also be switched between intermediate oxidized states by controlling the fraction of oxidized ferrocene
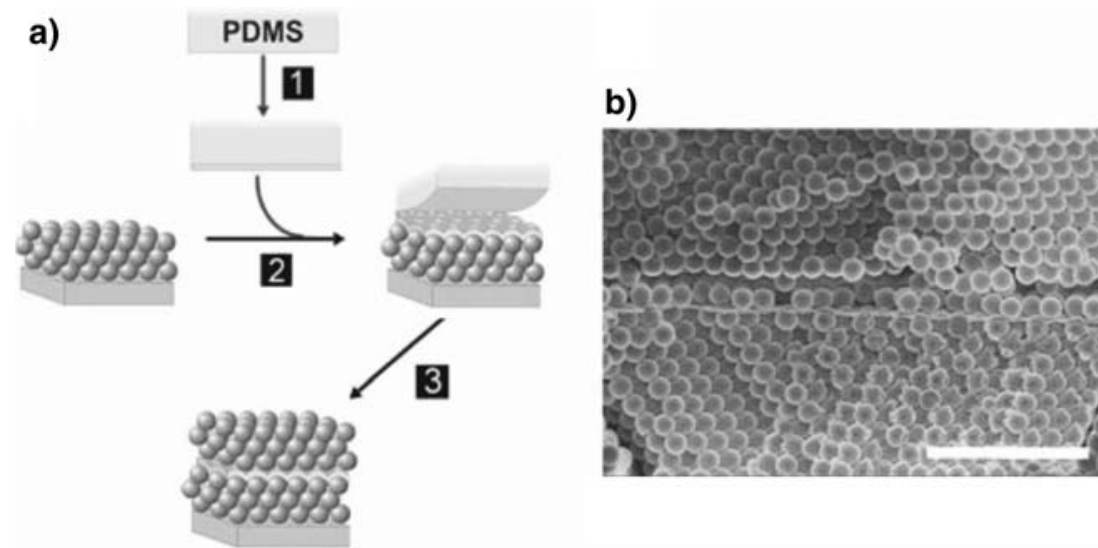

Fig. 13. Illustration of the incorporation of PFS PEMs into CPCs: (a) Schematic illustration of sample preparation: (1) Growth of a PEM onto a flat PDMS stamp; (2) transfer printing of the PEM onto the bottom CPC; (3) crystallization of the top CPC. (b) Cross-sectional scanning electron microscopy image of a silica CPC with embedded PFS defect layer composed of PFS polyelectrolytes $\mathbf{5}$ and $\mathbf{9}$. Scale bar is $2 \mu \mathrm{m}$. Reproduced with permission from [34]. Copyright 2005 Wiley-VCH Verlag GmbH. 

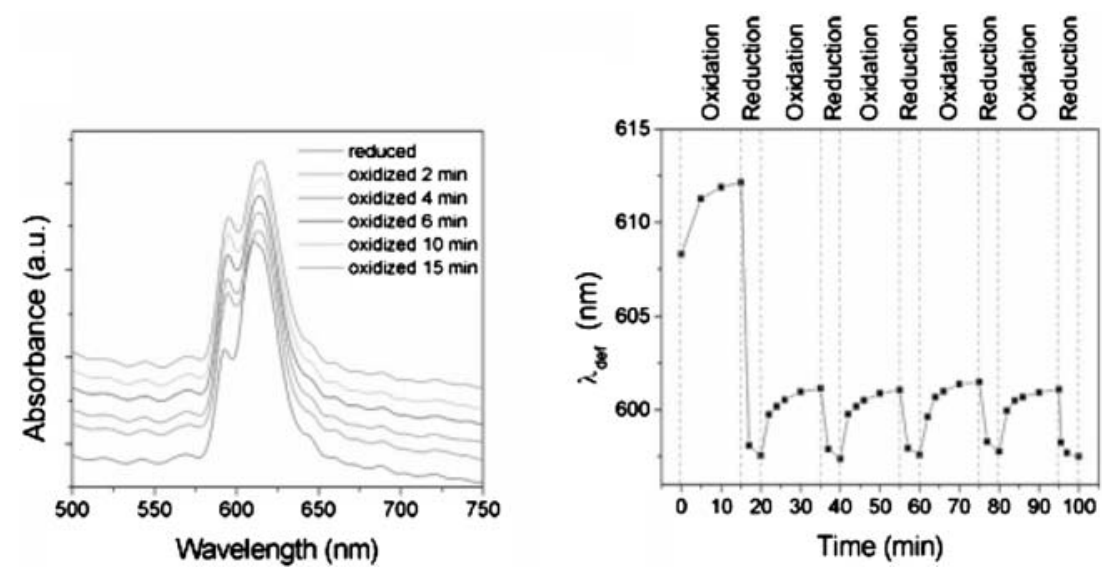

Fig. 14. (a) Transmission spectra of a PFS-defect CPC in the reduced and oxidized states; (b) changes of the wavelength position of the defect state during redox cycles. The polyelectrolyte species used here are PFS polyions $\mathbf{5}$ and $\mathbf{9}$. Reproduced with permission from [34]. Copyright 2005 Wiley-VCH Verlag GmbH.

units. These unique properties also imply potential applications such as optical sensors or PC-based laser sources [34].

\subsection{Redox-Active Smart Delivery Systems}

The development of polyelectrolyte nano- and microcapsules envisages increasingly interesting potential applications, in which biomedical delivery systems is one of the aspects that attracts utmost attention. For multilayer capsules, a delivery system involves the encapsulation of materials into the hollow shells. Normally there are two methods to realize encapsulation. One way is by using materials that are aimed to be encapsulated as the templating core material, e.g. directly employing biological materials such as protein aggregates. An alternative approach is to load preformed capsules by switching the permeability through their walls, or polymerization of monomers in the presence of empty shells [66]. Thus, many investigation efforts have been put into the development of microencapsulation technologies with permeation control by changing environmental conditions. A number of responsive PEMs that employ different stimuli have been proposed based on various "smart" polymers during the last few years [80]. The working principle of these systems often relies on external stimuli such as $\mathrm{pH}$ [81], ionic strength [81c, 82], temperature [83], light [84], magnetic field [85] and specific interactions [86] to regulate intermolecular interactions in the originally charge compensated multilayer structures.
In Section "Multilayer Capsules", we have described the successful incorporation of PFS polyelectrolytes into LBL fabricated microcapsules. The redox-responsive nature of PFS allowed us to further investigate a new stimulus, i.e. changing the redox state, on capsule wall permeability. Our study on fully organometallic PFS microcapsules revealed that upon chemical oxidation of these capsules using ferric chloride $\left(\mathrm{FeCl}_{3}\right)$, capsule permeability can be tuned very sensitively [42]. This results in fast capsule expansion accompanied by a drastic permeability increase, and finally full capsule disintegration. However, the introduction of an organometallic-organic hybrid polyelectrolyte microcapsule structure ensured the redox-responsive permeability change as well as preserving the spherical shape of these capsules. As shown in Fig. 15, PFS microcapsules bearing five bilayers of PFS polyelectrolytes (4/7) and one additional bilayer of redox-inert species poly(styrene sulfonate)/poly(allylamine hydrochloride) on the outmost wall display a dramatic change in molecular permeability [42].

\subsection{Macroporous Materials}

Macroporous materials refer to the structures that have pore sizes greater than $50 \mathrm{~nm}$ [87]. High porosity is of great interest since these systems can display many special physical (optical, mechanical) and chemical (reactivity, catalytic activity) properties. Various potential applications could potentially benefit from these structures as well, such as catalysis, separation and scaffolds [88]. However, most of the 

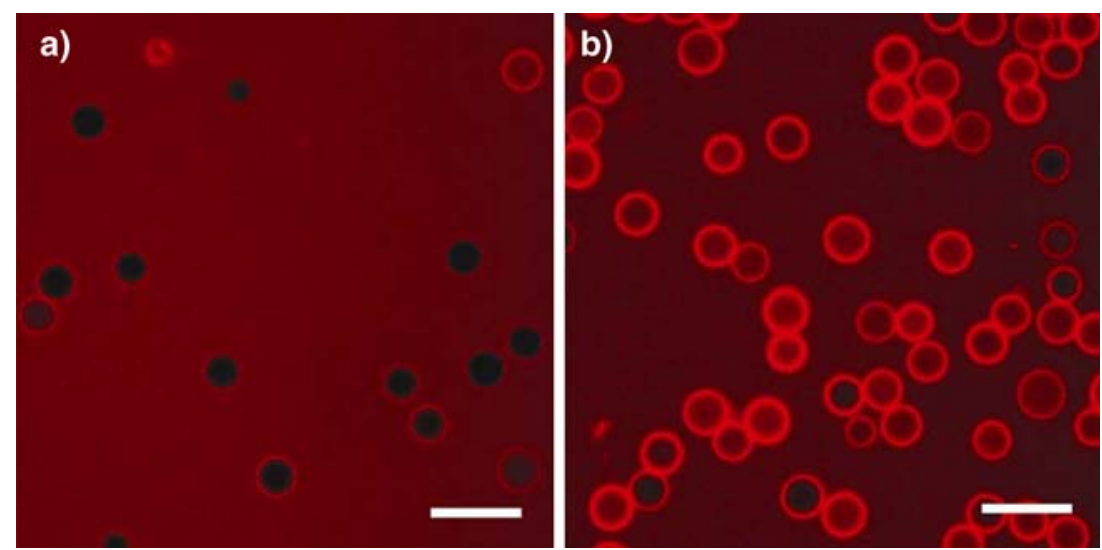

Fig. 15. CLSM images of left: $\left(\mathrm{PFS}^{-} / \mathrm{PFS}^{+}\right)_{5}(\mathrm{PSS} / \mathrm{PAH})_{1}$ microcapsules before oxidation; and right: the same capsules after oxidation by $\mathrm{FeCl}_{3}$ for $1 \mathrm{~h}$. Scale bar $=20 \mu \mathrm{m}$ for both images. Reproduced partly with permission from [42]. Copyright 2006 Nature Publishing Group.
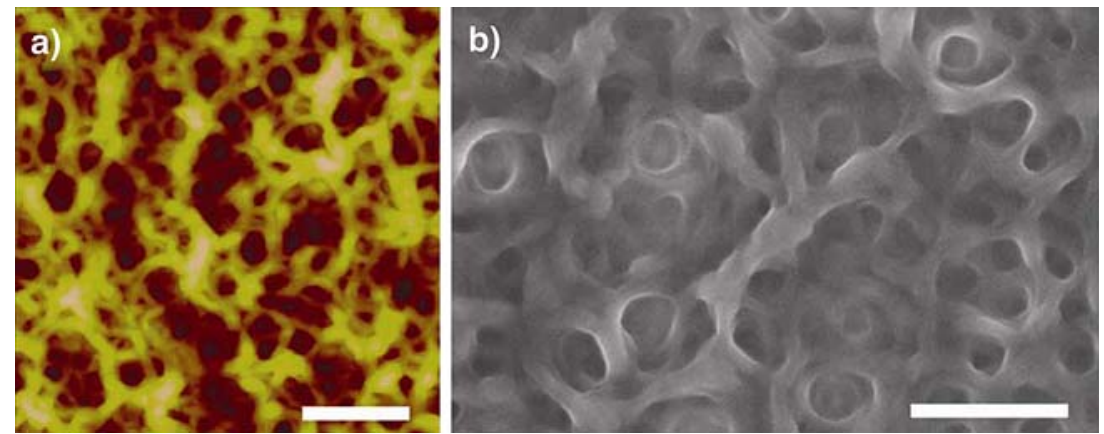

Fig. 16. Macroporous structures prepared from DNA and PFS polycation $\mathbf{4}$ by the electrostatic LBL process. Left: tapping mode AFM height image, $z$ range is $100 \mathrm{~nm}$; right: top-view scanning electron microscopy image. Scale bar $=500 \mathrm{~nm}$ for both images [92].

methods employed until now involve multi-step procedures [89]. Films containing DNA are also of great interest because they could have applications in sensing, diagnostics, electronics, and gene delivery [90]. As an anionic polyelectrolyte, DNA has successfully been incorporated into polyelectrolyte multilayer systems, for the aim of biocompatibility or the use as gene therapy carriers and sensor devices [91].

Very recently, we found when using DNA as an anionic polyelectrolyte and poly(ferrocenylsilane) polyelectrolytes $\mathbf{4}$ as the cationic components, stable thin films were obtained by their LBL electrostatic assembly [92]. However, unlike traditionally formed microporous multilayer structures, these films demonstrate unprecedented macroporous architectures (Fig. 16). This peculiar phenomenon was believed to be mainly the result of the persistence length mismatch of the two components as well as the extraordinary hydrophobic nature of the PFS backbone. The novel structure came from a simple "one-step" "bottom-up" self-assembly approach, which could offer a universal and facile route to the spontaneous fabrication of macroporous thin films containing other semi-flexible biopolymeric materials [92].

\section{CONCLUDING REMARKS}

The electrostatic LBL self-assembly technique has proven to be an attractive and versatile tool in the fabrication of thin films bearing specific functionalities. Incorporating poly(ferrocenylsilane) polyelectrolytes into multilayers assembled in this fashion, novel organometallic thin films with controlled thickness and molecular architectures were obtained. Applying the same thin film growth principle and colloidal templates, organometallic polyelectrolyte microcapsules featuring controlled molecular permeability were also successfully fabricated.

The unique molecular structures of PFS impart many special properties to these organometallic thin 
films. The redox-responsive nature of PFS provides plenty of opportunities for exploring application potentials related to the stimuli-responsiveness of PFS thin films and microcapsules. Selective deposition of PFS multilayers onto patterned substrates may be valuable for creating etch barriers in nanofabrication. Future work is expected to further explore these special functionalities and develop new systems that may bear multiple active molecules and can respond to multiple stimuli.

\section{ACKNOWLEDGEMENTS}

The University of Twente, the MESA ${ }^{+}$Institute for Nanotechnology of the University of Twente, the Dutch Science Foundation for Chemical Research NWO-CW and NanoImpuls, a Nanotechnology Program of the Ministry of Economic Affairs of The Netherlands are acknowledged for financial support.

\section{REFERENCES}

1. S. Barlow and D. O'Hare, Chem. Rev. 97, 637 (1997).

2. For a review see: (a) I. Manners, Synthetic Metal-containing Polymers (Wiley-VCH, Weinheim, 2004). (b) K. Kulbaba and I. Manners, Macromol. Rapid Commun. 22, 711 (2001).

3. (a) H. Rosenberg and M. D. Rausch, US Patent 3,060,215 (1962). (b) E. W. Neuse and H. J. Rosenberg, J. Macromol. Sci. C4, 1 (1970).

4. D. A. Foucher, B. Z. Tang, and I. Manners, J. Am. Chem. Soc. 114, 6246 (1992)

5. (a) R. Rulkens, A. J. Lough and I. Manners, J. Am. Chem. Soc. 116, 797 (1994). (b) Y. Z. Ni, R. Rulkens, J. K. Pudelski and I. Manners, Macromol. Rapid Commun. 16, 637 (1995).

6. I. Manners, Chem. Commun. 857 (1999).

7. I. Korczagin, R. G. H. Lammertink, M. A. Hempenius, S. Golze, and G. J. Vancso, Adv. Polym. Sci. 200, 91 (2006).

8. R. G. H. Lammertink, M. A. Hempenius, V. Z.-H. Chan, E. L. Thomas, and G. J. Vancso, Chem. Mater. 13, 429 (2001).

9. I. Korczagin, S. Golze, M. A. Hempenius, and G. J. Vancso, Chem. Mater. 15, 3663 (2003).

10. J. Y. Cheng, C. A. Ross, V. Z.-H. Chan, E. L. Thomas, R. G. H. Lammertink, and G. J. Vancso, Adv. Mater. 13, 1174 (2001).

11. (a) C. Hinderling, Y. Keles, T. Stöckli, H. F. Knapp, T. de los Arcos, P. Oelhafen, I. Korczagin, M. A. Hempenius, G. J. Vancso, R. Pugin and H. Heinzelmann, Adv. Mater. 16, 876 (2004). (b) S. Lastella, Y. J. Jung, H. C. Yang, R. Vajtai, P. M. Ajayan, C. Y. Ryu, D. A. Rider and I. Manners, J. Mater. Chem. 14, 1791 (2004).

12. M. I. Giannotti, H. Lv, Y. Ma, M. P. Steenvoorden, A. R. Overweg, M. Roerdink, M. A. Hempenius, and G. J. Vancso, J. Inorg. Organomet. Polym. Mater. 15, 527 (2005).

13. (a) D. Foucher, R. Ziembinski, R. Petersen, J. Pudelski, M. Edwards, Y. Ni, J. Massey, C. R. Jaeger, G. J. Vancso and I. Manners, Macromolecules 27, 3992 (1994). (b) R. Rulkens, A. J. Lough, I. Manners, S. R. Lovelace, C. Grant and W. E. Geiger, J. Am. Chem. Soc. 118, 12683 (1996). (c) M. Péter, M.
A. Hempenius, E. S. Kooij, T. A. Jenkins, S. J. Roser, W. Knoll and G. J. Vancso, Langmuir, 20, 891 (2004).

14. M. Péter, R. G. H. Lammertink, M. A. Hempenius, and G. J. Vancso, Langmuir 21, 5115 (2005).

15. (a) S. Zou, Y. Ma, M. A. Hempenius, H. Schönherr and G. J. Vancso, Langmuir 20, 6278 (2004). (b) S. Zou, M. A. Hempenius, H. Schönherr and G. J. Vancso, Macromol. Rapid Commun. 27, 103 (2006). (c) S. Zou, I. Korczagin, M. A. Hempenius, H. Schönherr and G. J. Vancso, Polymer 47, 2483 (2006).

16. D. A. Foucher, R. Ziembinski, B. Z. Tang, P. M. Macdonald, J. Massey, C. R. Jaeger, G. J. Vancso and I. Manners, Macromolecules 26, 2878 (1993).

17. M. T. Nguyen., A. F. Diaz, V. V. Dement'ev, and K. H. Pannell, Chem. Mater. 5, 1389 (1993).

18. K. N. Power-Billard and I. Manners, Macromolecules 33, 26 (2000).

19. M. A. Hempenius, N. S. Robins, R. G. H. Lammertink, and G. J. Vancso, Macromol. Rapid Commun. 22, 30 (2001).

20. M. A. Hempenius and G. J. Vancso, Macromolecules 35, 2445 (2002).

21. Z. Wang, A. Lough, and I. Manners, Macromolecules 35, 7669 (2002).

22. M. A. Hempenius, F. F. Brito, and G. J. Vancso, Macromolecules 36, 6683 (2003).

23. P. Köpf-Maier, H. Köpf, and E. W. Neuse, Angew. Chem. Int. Ed. 23, 456 (1984).

24. (a) R. Resendes, J. Massey, H. Dorn, M. A. Winnik and I. Manners, Macromolecules 33, 8 (2000). (b) K. N. Power-Billard and I. Manners, Macromol. Rapid Commun. 23, 607 (2002). (c) K. N. Power-Billard, R. J. Spontak and I. Manners, Angew. Chem. Int. Ed. 43, 1260 (2004). (d) X. S. Wang, M. A. Winnik and I. Manners, Macromol. Rapid Commun. 23, 210 (2002).

25. (a) G. Decher and J.-D. Hong, Macromol. Chem. Macromol. Symp. 46, 321 (1992). (b) G. Decher and J.-D. Hong, Thin Solid Films 210-211, 831 (1992).

26. G. Decher, and J. B. Schlenoff eds.,, Multilayer Thin Films (Wiley-VCH, Weinheim, 2003).

27. (a) M. Ferreira and M. F. Rubner, Macromolecules 28, 7107 (1995). (b) J. H. Cheng, A. F. Fou and M. F. Rubner, Thin Solid Films 244, 985 (1994). (c) G. Ladam, C. Gergely, B. Senger, G. Decher, J. C. Voegel, P. Schaaf and F. J. G. Cuisinier, Biomacromolecules 1, 674 (2000).

28. E. Donath, G. B. Sukhorukov, F. Caruso, S. A. Davis, and H. Möhwald, Angew. Chem. Int. Ed. 37, 2201 (1998).

29. N. P. Reddy, H. Yamashita and M. Tanaka, J. Chem. Soc. Chem. Commun. 2263 (1995).

30. (a) P. Gómez-Elipe, P. M. Macdonald, I. Manners, Angew. Chem. Int. Ed. 36, 762 (1997). (b) P. Gómez-Elipe, R. Resendes, P. M. Macdonald and I. Manners, J. Am. Chem. Soc. 120, 8348 (1998).

31. F. Jäkle, Z. Wang, and I. Manners, Macromol. Rapid Commun. 21, 1291 (2000).

32. (a) I. C. Kwon, Y. H. Bae, S. W. Kim, Nature 354, 291 (1991). (b) R. Yerushalmi, A. Scherz, M. E. van der Boom and H. B. Kraatz, J. Mater. Chem. 15, 4480 (2005).

33. (a) J. K. Pudelski, D. A. Foucher, C. H. Honeyman, P. M. Macdonald, I. Manners, S. Barlow and D. O'Hare, Macromolecules 29, 1894 (1996). (b) A. C. Arsenault, H. Miguez, V. Kitaev, G. A. Ozin and I. Manners, Adv. Mater. 15, 503 (2003).

34. F. Fleischhaker, A. C. Arsenault, Z. Wang, V. Kitaev, F. C. Peiris, G. von Freymann, I. Manners, R. Zentel, and G. A. Ozin, Adv. Mater. 17, 2455 (2005).

35. N. Tétreault, A. C. Arsenault, A. Mihi, S. Wong, V. Kitaev, I. Manners, H. Miguez, and G. A. Ozin, Adv. Mater. 17, 1912 (2005). 
36. M. Ginzburg, J. Galloro, F. Jäkle, K. N. Power-Billard, S. Yang, I. Sokolov, C. N. C. Lam, A. W. Neumann, I. Manners, and G. A. Ozin, Langmuir 16, 9609 (2000).

37. M. A. Hempenius, M. Péter, N. S. Robins, E. S. Kooij, and G. J. Vancso, Langmuir 18, 7629 (2002).

38. J. Halfyard, J. Galloro, M. Ginzburg, Z. Wang, N. Coombs, I. Manners and G. A. Ozin, Chem. Commun. 1746 (2002).

39. M. Ferreira, J. H. Cheung, and M. F. Rubner, Thin Solid Films 244, 806 (1994).

40. I. Manners, Adv. Organomet. Chem 37, 131 (1995).

41. (a) S. T. Dubas, J. B. Schlenoff, Macromolecules 32, 8153 (1999). (b) P. Bertrand, A. Jonas, A. Laschewsky, R. Legras, Macromol. Rapid Commun. 21, 319 (2000).

42. Y. Ma, W.-F. Dong, M. A. Hempenius, H. Möhwald, and G. J. Vancso, Nat. Mater 5, 724 (2006).

43. Y. Ma, W.-F. Dong, E. S. Kooij, M. A. Hempenius, H. Möhwald and G. J. Vancso, Soft Matter, submitted.

44. R. Steitz, V. Leiner, R. Siebrecht, and R. von Klitzing, Colloid Surf. A Physiochem. Eng. Asp. 163, 63 (2000).

45. H. Lee, L. J. Kepley, H.-G. Hong, S. Akhter, and T. E. Mallouk, J. Phys. Chem. 92, 2597 (1988).

46. A. J. Bard eds.,, Electroanalytical Chemistry (Marcel Dekker, New York, 1996) 109-335.

47. G. Z. Sauerbrey, Z. Phys. 155, 206 (1959).

48. (a) D. Laurent and J. B. Schlenoff, Langmuir 13, 1552 (1997). (b) M. C. Hsieh, R. J. Farris and T. J. McCarthy, Macromolecules 30, 8453 (1997).

49. S. Joly, R. Kane, L. Radzilowski, T. Wang, A. Wu, R. E. Cohen, E. L. Thomas, and M. F. Rubner, Langmuir 16, 1354 (2000).

50. W. Chen and T. J. McCarthy, Macromolecules 30, 78 (1997).

51. D. Yoo, S. S. Shiratori, and M. F. Rubner, Macromolecules 31, 4309 (1998)

52. S. T. Dubas and J. B. Schlenoff, Langmuir 17, 7725 (2001).

53. Y. Lvov, G. Decher, and H. Möhwald, Langmuir 9, 481 (1993).

54. H. C. Yang, K. Aoki, H.-G. Hong, D. D. Sackett, M. F. Arendt, S.-L. Yau, C. M. Bell, and T. E. Mallouk, J. Am. Chem. Soc. 115, 11855 (1993).

55. G. B. Sukhorukov, E. Donath, S. Moya, A. S. Susha, A. Voigt, J. Hartmann, and H. Möhwald, J. Microencapsul. 17, 177 (2000).

56. P. Cyr, D. Rider and I. Manners, in Macromolecules Containing Metal and Metal-like Elements, A. S. Abd-El-Aziz, C. E. Carraher Jr., C. U. Pittman Jr., J. E. Sheats and M. Zeldin eds. (John Wiley \& Sons, Inc., Hoboken, New Jersey, 2004), Vol. 2, Chap. 3.

57. (a) A. A. Antipov, D. Shchukin, Y. Fedutik, A. I. Petrov, G. B. Sukhorukov and H. Möhwald, Coll. Surf. A Physicochem. Eng. Asp. 224, 175 (2003). (b) H. Zhu, E. W. Stein, Z. Lu, Y. M. Lvov and M. J. McShane, Chem. Mater. 17, 2323 (2005).

58. Z. Dai, L. Dähne, H. Möhwald, and B. Tiersch, Angew. Chem. Int. Ed. 41, 4019 (2002).

59. M. Houska and E. Brynda, J. Coll. Interf. Sci. 188, 243 (1997).

60. Y. Lvov, K. Ariga, I. Ichinose, and T. Kunitake, J. Am. Chem. Soc. 117, 6117 (1995).

61. Y. Sun, X. Zhang, C. Sun, B. Wang, and J. Shen, Macromol. Chem. Phys. 197, 147 (1996).

62. F. van Ackern, L. Krasemann, and B. Tieke, Thin Solid Films 327-329, 762 (1998).

63. T. Cassagneau and J. H. Fendler, Adv. Mater. 10, 877 (1998).

64. J. Sun, Y. Sun, S. Zou, X. Zhang, C. Sun, Y. Wang, and J. Shen, Macromol. Chem. Phys. 200, 840 (1999).
65. R. Pommersheim, J. Schrenzenmeir, and W. Vogt, Macromol. Chem. Phys. 195, 1557 (1994).

66. (a) L. Dähne, S. Leporatti, E. Donath and H. Möhwald, $J$. Am. Chem. Soc. 123, 5431 (2001). (b) C. Gao, S. Leporatti, S. Moya, E. Donath and H. Möhwald, Chem. Eur. J. 9, 915 (2003).

67. S. L. Clark and P. T. Hammond, Adv. Mater. 10, 1515 (1998).

68. P. T. Hammond, Adv. Mater. 16, 1271 (2004).

69. Y. Xia and G. M. Whitesides, Angew. Chem. Int. Ed. 37, 550 (1998).

70. P. T. Hammond and G. M. Whitesides, Macromolecules 28, 7569 (1995).

71. S. Y. Yang and M. F. Rubner, J. Am. Chem. Soc. 124, 2100 (2002).

72. F. Hua, J. Shi, Y. Lvov, and T. Cui, Nano Lett. 2, 1219 (2002).

73. J. Park and P. T. Hammond, Adv. Mater. 16, 520 (2004).

74. R. G. H. Lammertink, M. A. Hempenius, J. E. van den Enk, V. Z.-H. Chan, E. L. Thomas, and G. J. Vancso, Adv. Mater. 12, 98 (2000).

75. K. S. Schanze, T. S. Bergstedt, B. T. Hauser, and C. S. P. Cavalaheiro, Langmuir 16, 795 (2000).

76. (a) S. Jone, Phys. Rev. Lett. 58, 2486 (1987). (b) E. Yablonovitch, Phys. Rev. Lett. 58, 2059 (1987).

77. (a) J. D. Joannopoulos, P. R. Villeneuve and S. H. Fan, Nature 386, 143 (1997). (b) C. Lopez, Adv. Mater. 15, 1679 (2003).

78. E. Yablonovitch, T. J. Gmitter, R. D. Meade, A. M. Rappe, K. D. Brommer, and J. D. Joannopoulos, Phys. Rev. Lett. 67, 3380 (1991).

79. F. Fleischhaker, A. C. Arsenault, V. Kitaev, F. C. Peiris, G. von Freymann, I. Manners, R. Zentel, and G. A. Ozin, J. Am. Chem. Soc. 127, 9318 (2005).

80. S. A. Sukhishvili, Curr. Opin. Coll. Inter. Sci. 10, 37 (2005).

81. (a) J. Hiller, J. D. Mendelsohn and M. F. Rubner, Nat. Mater. 1, 59 (2002). (b) G. B. Sukhorukov, A. A. Antipov, A. Voigt, E. Donath and H. Möhwald, Macromol. Rapid Commun. 22, 44 (2001). (c) S. A. Sukhishvili and S. Granick, J. Am. Chem. Soc. 122, 9550 (2000)

82. A. A. Antipov, G. B. Sukhorukov, and H. Möhwald, Langmuir 19, 2444 (2003).

83. K. Glinel, G. B. Sukhorukov, H. Möhwald, V. Khrenov, and K. Tauer, Macromol. Chem. Phys. 204, 1784 (2003).

84. B. Radt, T. A. Smith, and F. Caruso, Adv. Mater. 16, 2184 (2004).

85. Z. Lu, M. D. Prouty, Z. Guo, V. O. Golub, C. S. S. R. Kumar, and Y. M. Lvov, Langmuir 21, 2042 (2005).

86. H. Inoue, K. Sato, and J.-i. Anzai, Biomacromolecules 6, 27 (2005).

87. A. Imhof and D. J. Pine, Nature 389, 948 (1997).

88. B. T. Holland, C. F. Blanford, T. Do, and A. Stein, Chem. Mater 11, 795 (1999)

89. (a) O. D. Velev and E. W. Kaler, Adv. Mater. 12, 531 (2000). (b) U. H. F. Bunz, Adv. Mater. 18, 973 (2006).

90. E. M. Boon, D. M. Ceres, T. G. Drummond, M. G. Hill, and J. K. Barton, Nat. Biotechnol. 18, 1096 (2000).

91. (a) Y. Lvov, G. Decher and G. Sukhorukov, Macromolecules 26, 5396 (1993). (b) A. P. R. Johnston, E. S. Read and F. Caruso, Nano Lett. 5, 953 (2005). (c) O. I. Vinogradova, O. V. Lebedeva, K. Vasilev, H. Gong, J. Garcia-Turiel and B.-S. Kim, Biomacromolecules 6, 1495 (2005).

92. Y. Ma, W.-F. Dong, M. A. Hempenius, H. Möhwald and G. J. Vancso, Angew. Chem. Int. Ed. (in press). 